\title{
Textbook Evaluation of a General English Textbook for Senior Foreign Language Learners: Application of a Textbook Evaluation Checklist
}

\author{
Luis Miguel Dos Santos
}

Woosong Language Institute, Woosong University, Daejeon, South Korea.

Email:Luismigueldossantos@yahoo.com Tel:82-010-3066-7818

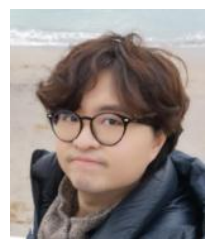

\begin{abstract}
English language learning is one of the most famous and popular learning destinations and interests for many adults and returning students in the East Asian region, particularly for senior citizens who want to expand their horizon during late adulthood. Although there are many foreign language learning schools, self-learning books, video-oriented materials, and even social media channels for students who want to study an additional language during their leisure time, locating a useful and appropriate textbook or related material is the most important step to increase learner's interests and overall performance. The current study employed a textbook evaluation checklist of a well-known General English textbook material in South Korea. The results of this study indicated the learning behaviours of Korean senior citizens, outlined the application of a textbook evaluation checklist, and evaluated the effectiveness and usefulness of a General English textbook. School leaders, teachers, and department heads can employ this textbook evaluation checklist to evaluate their teaching and learning materials for the appropriateness.
\end{abstract}

Keywords: Adult education, English language learning, Foreign language learning, Learner's behaviours, Senior citizens, Textbook evaluation checklist.

Citation | Luis Miguel Dos Santos (2020). Textbook Evaluation of a General English Textbook for Senior Foreign Language Learners: Application of a Textbook Evaluation Checklist. Journal of Education and e-Learning Research, 7(1): 22-27.

History:

Received: 11 October 2019

Revised: 14 November 2019

Accepted: 19 December 2019

Published: 10 February 2020

Licensed: This work is licensed under a Creative Commons

Attribution 3.0 License (cc) E

Publisher: Asian Online Journal Publishing Group
Funding: This research is supported by Woosong Academic Funding 2020 Competing Interests: The author declares that there are no conflicts of interests regarding the publication of this paper.

Transparency: The author confirms that the manuscript is an honest, accurate, and transparent account of the study was reported; that no vital features of the study have been omitted; and that any discrepancies from the study as planned have been explained.

Ethical: This study follows all ethical practices during writing.

\section{Contents}

1. Introduction 23

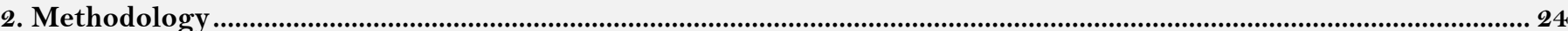

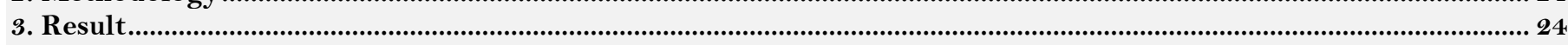

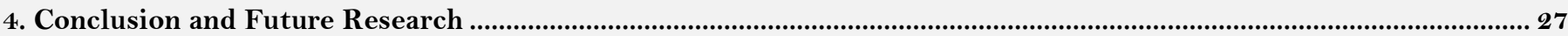

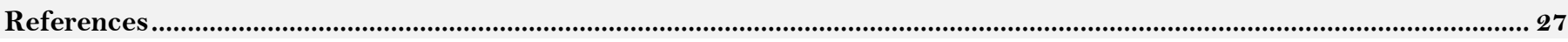




\section{Contribution of this paper to the literature}

This study contributes to the field of textbook evaluation, teaching and learning material studies, foreign language learning, adult learning, and senior learning behaviours. Readers will gain knowledge about how textbook materials can be the key to influence learners' behaviours and motivation.

\section{Introduction}

For nearly a century, English language is one of the most popular foreign languages for global citizens to learn and master due to the extensive developments of the American industry, expansions of the information technology, and prosperities of the business trading across the continents (DeWaelsche, 2015). Although other foreign languages, such as French, Spanish, Portuguese, and Mandarin Chinese, may take the roles as the regional languages within a few regions and countries, English language skill is still considered as the conversational and communicative language across the international communities (Dos Santos, 2018).

English language learning is one of the most famous and popular learning destinations and interests for many adults and returning students in the East Asian region, particularly for senior citizens who want to expand their horizon during late adulthood. Although there are many foreign language learning schools, self-learning books, video-oriented materials, and even social media channels for learners who want to study an additional language during their leisure time, locating a useful and appropriate textbook or related material is the most important step to increase learners' interests and overall performances (Dos Santos, 2019b).

In the field of hospitality, service management, retail industry, and hotel operation, front-line workers, managerial professional, back-office staff, and even executive leaders are expected to have reasonable English language skills in order to handle the daily operation and managerial direction. As a result, many companies and organisations, non-profit organisations, governmental agencies, language schools, and university departments host a large number of English language courses for learners with different purposes and needs (Fielden and Rico, 2017). For the fresh secondary school graduates and university graduates, the school educational plans and curriculum should implement a reasonable amount of English language modules and even additional language modules for both career and educational purposes (Day and Krzanowski, 2010). In other words, fresh graduates at both secondary and university-level are well-prepared for potential English language challenges and problems in many contemporary societies. However, senior citizens and mid-aged residents who might not be able to receive solid education and learning opportunities due to the social development during the last century. These groups of individuals may not able to handle and perform any additional languages other than their native language, particularly for many developing countries and regions in the Far East region.

Due to the shortage of human resources and skilled professionals in the current South Korean markets and business environments, a large number of senior citizens need to return to the business markets for the demands of human resources. From the mid-2000s, the South Korean business environment has been developed due to the developments of globalisation, entertainment, and huge international hospitality market. A large number of largesize shopping centres, mid-size businesses, and even small-size family business companies have been established to meet the demands of the current business environment. However, once the young generations have been placed into the business market, senior citizens with no foreign language skills may need to enter the workforce due to the aggressive shortage of human. As a result, a large number of foreign language teaching and learning courses, language schools, and teaching and learning materials are found in the South Korean environment resources (Lee and Lee, 2019). However, without effective and appropriate teaching and learning materials for foreign language learning can be strong limitations to increase the overall interests and performance of the learners, particularly for senior citizens who may not receive any formal education and training for more than three decades. Therefore, the effectiveness and the appropriateness of teaching and learning materials are one of the most important elements beyond the classroom management and knowledge acquisition (Dos Santos, 2019a).

\subsection{Significance of this Study}

There are five significant elements of this study. First, unlike traditional-age students, mid-level professionals, managerial leaders, senior citizens usually have fewer motivations and self-learning techniques due to ageing and heavy responsibilities. In order to increase the motivation, teachers and school administrators should locate and provide appropriate textbook and teaching and learning materials (You and Dörnyei, 2016). Particularly for senior citizens who might not receive formal education and training for decades, how to catch the attention and interest of these groups of learners are very important.

Second, there are different purposes of foreign language teaching and learning, such as English for Specific Purposes (McNamara, 1990), English for Academic Purposes (Hutchinson and Waters, 1987) and English for General Purposes (Pan and Block, 2011), etc. As different directions have their own goals and missions, the teaching and learning strategies, classroom management, textbook and materials contributions, and interactive exercises are not the same due to the various purposes and student population. Although each textbook and related exercise book may provide pre-set exercises and training for different skills, teachers and school administrators may find the practices are not appropriate for particular groups of learners.

Third, the current textbook evaluation checklist (Dos Santos, 2017; 2019a) has been employed in different teaching and learning environments, situations, and school backgrounds, and populations. As most of the users and school administrators who have employed and applied into their textbook evaluation process provided positive feedback, the current study decided to employ the same textbook evaluation checklist to evaluate a textbook material for senior citizens who have two years of English language learning experience.

Fourth, the current textbook evaluation checklist (Dos Santos, 2017; 2019a) one of the most popular evaluations in the contemporary educational database. Therefore, the completion of this study employed this wellknown textbook evaluation checklist and showed readers how this textbook evaluation checklist could be useful in their school environment. 
Fifth, the current evaluated textbook material is one of the most popular English language teaching and learning materials internationally. However, it is important to understand the feedback and opinions from the textbook users who have completed all modules and chapters. Therefore, throughout the applications of this textbook evaluation checklist, the readers can understand whether this textbook is appropriate in their unique classroom environment internationally.

\section{Methodology}

\subsection{Participants}

The participants of this study were 200 senior citizens who have completed two years of English language learning in South Korea. The native language of these participants was the Korean language. None can speak any additional languages before the completion of the first-year English language course.

2.2. Site

Due to the rapid development of the business environment and society in South Korea, a large number of companies and organisations, non-profit organisations, governmental agencies, language schools, and university departments host similar English language courses for different types of learners. However, due to the nature of this study (i.e. textbook evaluation and senior citizens), the researcher only located five language schools in South Korea that met the requirements and criteria of this study.

\subsection{The Textbook Material}

The teaching and learning material to be evaluated was Breakthrough Plus (Level 2) by Craven (2016). Based on the current Common European Framework of Reference for Languages (CEFR) scale, the current teaching and learning material was created for A1 and A2 level learners who may have one or two years of English language experience. In the current educational environment, a large number of textbook evaluation checklist available, different textbook evaluation checklists may have their specific focuses and purposes for particular subjects, majors, and fields. In order to exercise the current study about English for General Purposes for senior citizens in the South Korean environment, the study employed the textbook evaluation checklist (Dos Santos, 2017; 2019a) that was created exclusively for English language teaching and learning.

The evaluation comprised ten items with an optional written comment for each item about the effectiveness, usefulness, and appropriateness of the material(s) that is currently used in the classroom environment. Due to the language barrier of the respondents of the survey (i.e. senior citizens in South Korea), the survey has been translated into the Korean language.

\subsection{Procedure}

First, the current evaluated textbook material (Craven, 2016) is one of the most popular English language teaching and learning materials in the current South Korean educational environment. Although the researcher does not have any statistics which locations and classrooms are using this textbook material, the researcher believed that the market share of this textbook is high enough for a meaningful report. Therefore, after the researcher sent the invitation of researcher for this textbook material, more than 30 sites indicated that they are using this textbook for some types of courses.

Second, after the researcher sent the invitation for research, 35 site administrators agreed for participation. For the nature of this study, three out of the 35 hosted English courses for senior citizens with this particular textbook.

Third, the researcher forwarded the research protocol, the survey in both English and Korean languages, unsigned agreements with details and potential risks, and contact information of the researcher to the site administrators for further progress.

Fourth, once the site administrators approved the study, the researcher sent the paper-based materials to each site. During the last lesson of the courses, the site administrator(s) contributed the survey to the participants (i.e. senior citizens) for the feedback. As a result, 200 valid surveys have been collected.

\section{Result}

This study aimed to understand the effectiveness, feedback, usefulness, and appropriateness of a famous English language textbook material for General English learning for senior citizens in the South Korean educational environment. The survey developer (Dos Santos, 2017; 2019a) indicated that researchers and users could apply this survey to both learners and teachers for a comprehensive result. However, the researcher tended to collect feedback from senior citizens who are using this textbook for English language learning during their late adulthood. Although the feedback from teachers and school administrators may enhance the result, the feedback from senior citizens is unique and significant for this result and potential readers. The responses provided by the participants were rated from 5 (strongly agree / SA); 4 (agree / A); 3 (neutral / N); 2 (disagree /D); to 1 (strongly disagree / SD). Survey details has been listed in Table 1 .

The survey data outlined some useful information and finding the overall performance and feedback of the current evaluated textbook material. It is worth noting that almost all learners of this textbook material believed the overall applications and performances of this textbook material were useful, contemporary, applicable, useful, realistic, and appropriate of their purposes and expectations as senior learners of English language in the South Korean environment. 
Table-1. Survey result.

\begin{tabular}{|c|c|c|c|c|c|}
\hline Checklist Question & $\mathbf{S A}(5)$ & $A(4)$ & $\mathbf{N}(3)$ & $\mathrm{D}(\mathbf{2})$ & $\mathrm{SD}(1)$ \\
\hline \multirow[t]{2}{*}{ 1. The textbook is easy to access, particularly the price } & 200 & - & - & - & - \\
\hline & $100 \%$ & - & - & - & - \\
\hline \multirow{2}{*}{$\begin{array}{l}\text { 2. The textbook materials and exercises are contemporary and } \\
\text { applicable }\end{array}$} & 176 & 20 & 4 & - & - \\
\hline & $88 \%$ & $10 \%$ & $2 \%$ & - & - \\
\hline \multirow[b]{2}{*}{ 3. The students' exercise is applicable and useful } & 132 & 45 & 23 & - & - \\
\hline & $66 \%$ & $22.5 \%$ & $11.5 \%$ & & \\
\hline \multirow{2}{*}{$\begin{array}{l}\text { 4. The textbook provides practices about essential pronunciation } \\
\text { training }\end{array}$} & 146 & 50 & 4 & - & - \\
\hline & $73 \%$ & $25 \%$ & $2 \%$ & - & - \\
\hline \multirow[t]{2}{*}{ 5. The textbook is well organised } & 146 & 48 & 6 & - & - \\
\hline & $73 \%$ & $24 \%$ & $3 \%$ & - & - \\
\hline \multirow[b]{2}{*}{ 6. The textbook offers a balance between activities and lessons } & 176 & 21 & 3 & - & - \\
\hline & $88 \%$ & $10.5 \%$ & $1.5 \%$ & - & - \\
\hline \multirow{2}{*}{$\begin{array}{l}\text { 7. The activities encourage learners to learn, communicate and } \\
\text { participate }\end{array}$} & 165 & 27 & 8 & - & - \\
\hline & $82.5 \%$ & $13.5 \%$ & $4 \%$ & - & - \\
\hline \multirow{2}{*}{$\begin{array}{l}\text { 8. The grammar and vocabulary are introduced in realistic } \\
\text { contexts }\end{array}$} & 129 & 74 & 7 & - & - \\
\hline & $64.5 \%$ & $37 \%$ & $3.5 \%$ & - & - \\
\hline \multirow[b]{2}{*}{ 9. The textbook offers a balance of four skills } & 147 & 50 & 3 & - & - \\
\hline & $73.5 \%$ & $25 \%$ & $1.5 \%$ & - & - \\
\hline \multirow[b]{2}{*}{ 10. The language usage is at the appropriated level of students } & 154 & 42 & 4 & - & - \\
\hline & $77 \%$ & $21 \%$ & $2 \%$ & - & - \\
\hline
\end{tabular}

\subsection{Checklist Results in Detail}

The first checklist question was: The textbook is easy to access, particularly the price. Surprisingly, $100 \%$ of the learners strongly believed the textbook material was affordable, particularly for senior citizens. Based on the major online retailers and textbook sellers on the internet, the paperback version of the textbook material costs $35,000 \mathrm{KRW}$ (\$30 USD), the current price of this textbook material was considered as expensive in most of the East Asian environment as most of the East Asian countries are developing countries. However, most of the learners believed this textbook material should worth its price due to the meaningful details, practices, and exercises. More than 150 participants expressed that the price of this textbook material is "understandable and reasonable as the information is meaningful and applicable" (Learner \#147) to many professional environments in South Korea. Also, more than 100 learners advocated that the price of this textbook material was "about average of most of the English language textbook and self-learned materials" (Learner \#38) in the current South Korean market. As a result, all learners believed this textbook material was affordable due to the overall application and usefulness of the learning practices and exercises. Therefore, the textbook material was ranked as top-tier material for General English learning, particularly for senior citizens in the South Korean environment.

Second checklist question was: The textbook materials and exercises are contemporary and applicable. Almost $90 \%$ of the learners believed that this textbook material and its related exercises were contemporary and applicable to their professional environment. Although the survey did not ask about the career pathways and occupations of the learners, the General English materials basically covered all essential parts and elements for beginners and intermediate learners in South Korea, particularly for senior citizens. Unlike other English for Specific Purposes and English for Academic Purposes textbook materials, the current textbook material focused on the General English learning which might meet the expectations and applications for most of the senior citizens in the society. Several learners indicated that the chapter details and speaking exercises applied to their daily life. For example, a learner expressed that he/she could express some oral conversations to his/her grandchildren, saying, "Unit 3 talked about housework and household duties, I always tell my grandchildren about cleaning and arranging. It is very useful and applicable" (Learner \#12). Several learners also believed that some chapters and conversations were useful for them to express their life-long voyage and experience to other people, such as, "a unit taught us how to express the most remarkable travel in our life. I learned some useful vocabulary to share with my classmates and friends" (Learner \#45). Based on the result, a large number of learners believed the textbook knowledge, details, and exercises were contemporary and applicable for daily conversation and use, particularly for senior citizens.

Third checklist question was: The students' exercise is applicable and useful. A total of $66 \%$ of the leaners chose strongly agree; $22.5 \%$ of the learners chose agree; and $11.5 \%$ of the learners chose neutral. In other words, nearly $90 \%$ of the total learners advocated that the exercises and practices from the textbook material were applicable and useful to their professional environment. However, it is worth noting that only $66 \%$ of the total learners strongly agreed and believed the textbook material was applicable and useful. The researcher indicated several comments from the learners who ranked neutral for this category. Several learners believed that exercise and practices tended to "focus on the daily life of young people and university students. Senior citizens usually do not go to the theme park for games" (Learner \#112). Another learner indicated that the examples and exercises tended to "focus on the environment in the United States, Europe, and western societies. I want to see some examples of South Korea" (Learner \#87). Based on some comments, the instructors might enhance and implement some additional examples, worksheets, and PowerPoint presentations which involved local cultures and expectations, in this case, South Korean, in order to meet and increase the learning experience of senior citizens who might not have extensive international living experience.

The fourth checklist question was: The textbook provides practices about essential pronunciation training. A total of $73 \%$ of the learners chose strongly agree; $25 \%$ of the learners chose agree; and only $2 \%$ of the learners chose neutral as their answers. Based on these results, almost all learners believed the pronunciation training was useful and appropriate. It is worth noting that the student's book came with an online version pronunciation and listening training which allowed learners to access the listening exercises via their cell phone applications and computer systems. Surprisingly, the researchers received 102 positive comments about the online version pronunciation and listening training of this textbook material. Many indicated that they could listen to the chapters, training, 
exercises, and conversations at home during leisure time as "many of us need to listen to the conversation multiple times for training” (Learner \#90). Several learners also believed without the listening training, they cannot practice their pronunciation skills at home, saying, "I can practice my pronunciation at home with my grandchildren. Both learn the same textbook at home" (Learner \#91).

It is worth noting that 95 learners indicated the online version of pronunciation and listening training was convenient as many of them did not own any CD readers and computers any more, saying, "I used to have a book comes with a CD, but I do not have any CD readers at my home. I cannot read it" (Learner \#22). In addition to the $\mathrm{CD}$ issues, many indicated that the contemporary textbook materials usually do not give them the CD. Only the teachers' version comes with the CD. Therefore, they cannot listen to the listening exercise during their leisure time, saying, "only the teachers can show us the CD previously. But now, I can listen to the exercise at home" (Learner \#34). Therefore, the upgraded technology does not only change the learning behaviours of youth and traditional-age students at the traditional school environments but also senior citizens could experience the innovative teaching and learning technique as technology has been implemented into learners' daily life.

The fifth checklist question was: The textbook is well organised. A total of $73 \%$ of the learners chose strongly agree; $24 \%$ of the learners chose agree; and $3 \%$ of the learners chose neutral. In terms of organisation, nearly 100 learners expressed that the orders of vocabulary, reading, listening, exercise, and written task always increased their interests and progressions. Many expressed similar comments about the cohesive orders from vocabulary to reading increased their knowledge base and applications, saying, "when I learned vocabulary, I can apply into the conversation right away" (Learner \#45). Similar comments also indicated that, "I can apply the vocabulary into the exercise immediately. At least I can use it. Not just learn and remember it" (Learner \#33). The positive feedback and opinions highly indicated that the organisation and order of this textbook material matched the needs and learning behaviours of these targeted learners.

The sixth checklist question was: The textbook offers a balance between activities and lessons. A total of $88 \%$ of the learners chose strongly agree; $10.5 \%$ of the learners chose agree; and $1.5 \%$ of the learners chose neutral. Nearly $90 \%$ of the learners believed this textbook material provided an excellent balance between activities and lessons. Only $1.5 \%$ of the learners did not have any positive or negative feedback. Such positive feedback and opinion advocated that the learners liked and enjoyed their lessons and courses with this current textbook material, like someone saying, "once I learned the grammar and vocabulary, I can apply it to the exercise and conversation" (Learner \#44). Similar opinions also indicated how the activities and lessons connected to learners' knowledge base, saying, "both activities and lessons are balanced and excellent to increase our understanding" (Learner \#48). Based on the data, most of the learners enjoyed the textbook material due to the excellent planning of the activities and lessons.

The seventh checklist question was: The activities encourage learners to learn, communicate and participate. A total of $82.5 \%$ of the learners chose strongly agree; $13.5 \%$ of the learners chose agree; and $4 \%$ of the learners chose neutral. Besides positive feedback and comments, only $4 \%$ of the learners expressed neutral opinions of this textbook material. It is worth noting that several learners provided extensive comments on this element due to the cultural background and expectation of South Korea or East Asian culture. For example, several learners indicated that East Asian learners tended to be listeners instead of speakers. Therefore, the intensive elements of communication and oral exercises might increase their stress and pressure, saying, "I tended to be a quiet listener, I always absorb my knowledge from listening. I do not like speaking. But the textbook has a lot of speaking and writing exercise” (Learner \#1). Similar comments also indicated the interactive exercises could be stressful to senior learners, saying, "although we are all students, we still have the gender-gaps and level differences. The interactive activities are not appropriate” (Learner \#163). Due to the cultural background and social expectation, teachers in different geographic regions and cultural backgrounds may adjust the interactive activities based on the needs of the learners.

The eighth checklist question was: The grammar and vocabulary are introduced in realistic contexts. A total of $64.5 \%$ of the learners chose strongly agree; $37 \%$ of the learners chose agree; and 3.5\% of the learners chose neutral. It is worth noting that only $64.5 \%$ of the learners believed the grammar and vocabulary are introduced in realistic contexts. More than 50 learners expressed that the grammar and vocabulary charts were not designed to meet the needs of senior citizens and their daily life, saying, "Unit 7 is about food and drink, parties, and French cuisine. South Korean senior citizens usually do not go to French parties and eat French food" (Learner \#89). Similar comments also indicated that the vocabulary tended to be westernised which senior citizens in South Korea might not able to apply into their daily life, saying, "I don't know what a Lantern Festival is. I cannot apply the vocabulary into my life" (Learner \#51). Based on their comments, teachers and instructors may enhance and implement some PowerPoint presentations, vocabulary lists, and exercises with local elements and applications in order to satisfy the needs of some learners with only local understanding and context.

The ninth checklist question was: The textbook offers a balance offour skills. A total of $73.5 \%$ of the learners chose strongly agree; $25 \%$ of the learners chose agree; and $1.5 \%$ of the learners chose neutral. Unlike other learners who want to expand their understanding and application of the foreign language, South Korean people tended to assess and evaluate their language skills based on exams and scores. Although speaking and listening skills are very important in foreign language learning, most of the learners emphasised their concerns about reading and writing skills. For example, nearly 80 learners expressed that they desired to enhance their reading and writing skills as these skills can be evaluated by exam papers, saying, "the speaking skill cannot be evaluated by exam paper. I am a good test taker. I want to have a good grade" (Learner \#58). Similar comments were found by saying, "Korean people like exams and tests, I want to have a good grade. Speaking is cannot be assessed” (Learner \#145).

The tenth checklist question was: The language usage is at the appropriated level of students. A total of $77 \%$ of the learners chose strongly agree; $21 \%$ of the learners chose agree; and $2 \%$ of the learners chose neutral. Most of the learners believed the language use was at the appropriate level of their language skills and levels. In fact, the current textbook material was designed for learners with two years of English language experience. Although some learners may find the exercises and practices were difficult due to the limited speaking skills, most of the learners indicated the material and exercise increased their overall skills and performances. For example, the 
textbook material always employed their exercises and applications into case studies and real-life experience. Therefore, the use of vocabulary and applications were able to employ into learners' daily life immediately. Although some learners believed the case studies and applications were westernised-oriented, many learners could adjust the environmental differences based on their experience, particularly for senior citizens.

\section{Conclusion and Future Research}

The completion of this study increased three advantages of the current educational database. First, the results provided a solid and clear understanding of feedback of the learning behaviours and expectations of senior citizens in the field of English language learning in the South Korean environment. Unlike traditional-age students, midlevel professionals, managerial leaders, senior citizens usually have fewer motivations and self-learning techniques due to ageing and heavy responsibilities. The study took this textbook material as a tool to outline the developments and improvements of senior citizens in different types of learning, such as foreign language learning, and vocational training.

Second, this study has employed a well-known textbook evaluation checklist of a General English textbook material in the South Korean environment. Although the sites and learners were all located in South Korea, the textbook material (Craven, 2016) is well-known in a large number of countries and cities in the Asian region. Therefore, the study provided a clear result to school administrators, teachers, department heads, and educators about the use and application of this textbook material. More importantly, from the feedback and opinion of the learners, these people can understand how to locate the appropriate textbook material for foreign language learners.

Third, this study also employed a well-known textbook evaluation checklist for evaluation. The study further expanded the application of this textbook evaluation checklist and indicated this textbook evaluation checklist was appropriate in teaching and learning material evaluation in the field of language learning and adult education. Although there are many similar textbook evaluation checklists available in the current educational database, only a few textbook evaluation checklists have been applied and evaluated. Therefore, this study further indicated the usefulness and effective of this textbook evaluation checklist (Dos Santos, 2017; 2019a).

\section{References}

Craven, M., 2016. Breakthrough plus. 2nd Edn., London, UK: Macmillan Education.

Day, J. and M. Krzanowski, 2010. English for specific purposes: An introduction. Cambridge, UK: Cambridge University Press.

DeWaelsche, S.A., 2015. Critical thinking, questioning and student engagement in Korean university English courses. Linguistics and Education, 32: 131-147.Available at: https://doi.org/10.1016/j.linged.2015.10.003.

Dos Santos, L.M., 2017. Evaluation of a foreign language textbook used in the greater boston region: An evaluation of a japanese as a foreign language textbook. International Research in Education, 5: 152-161.Available at: https://doi.org/10.5296/ire.v5i 1.10191.

Dos Santos, L.M., 2018. Foreign language learning beyond English: The opportunities of one belt, One Read (OBOR) Initiative. In N. Islam (Ed.), Silk Road to Belt Road. Singapore: Springer. pp: 175-189.

Dos Santos, L.M., 2019a. Evaluation checklist for english language teaching and learning for health science professionals. World Transactions on Engineering and Technology Education, 17(4): 431-436.

Dos Santos, L.M., 2019b. Textbook evaluation in the field engineering and applied sciences: A development and application for the use of university-level textbook. Journal of Engineering and Applied Sciences, 14(13): 4603-4606.Available at: https://doi.org/10.36478/jeasci.2019.4603.4606.

Fielden, L.V. and M. Rico, 2017. Culture and motivation in English for hospitality students: Why integrative motivation may be essential. Magazine of Languages for Specific Purposes, 23(2): 334-358.

Hutchinson, T. and A. Waters, 1987. English for specific purposes: A learning-centred approach. Cambridge, UK: Cambridge University Press.

Lee, J.S. and K. Lee, 2019. Perceptions of English as an international language by Korean English-major and non-English-major students. Journal of Multilingual and Multicultural Development, 40(1): 76-89.Available at: https://doi.org/10.1080/01434632.2018.1480628.

McNamara, T.F., 1990. Item response theory and the validation of an ESP test for health professionals. Language Testing, 7(1): 5276.Available at: https://doi.org/10.1177/026553229000700105.

Pan, L. and D. Block, 2011. English as a “global language” in China: An investigation into learners' and teachers' language beliefs. System, 39(3): 391-402.Available at: https://doi.org/10.1016/j.system.2011.07.011.

You, C.J. and Z. Dörnyei, 2016. Language learning motivation in China: Results of a large-scale stratified survey. Applied Linguistics, 37(4): 495-519.Available at: https://doi.org/10.1093/applin/amu046. 